Supplement of Hydrol. Earth Syst. Sci., 23, 2461-2479, 2019

https://doi.org/10.5194/hess-23-2461-2019-supplement

(C) Author(s) 2019. This work is distributed under

the Creative Commons Attribution 4.0 License.

(c) (1)
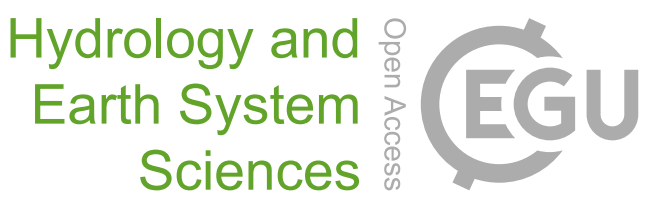

Supplement of

\title{
A partially coupled hydro-mechanical analysis of the Bengal Aquifer System under hydrological loading
}

Nicholas D. Woodman et al.

Correspondence to: Nicholas D. Woodman (n.d.woodman@ soton.ac.uk)

The copyright of individual parts of the supplement might differ from the CC BY 4.0 License. 


\section{Contents of this file}

\section{Introduction}

7 This Supporting Information provides illustration of (i) additional generic modelling results showing the effects of lithological

8 layering in the Bengal Aquifer System of the GMB floodplains (Figure S1, Table S1), (ii) the piezometer locations at Khulna

9 and Laksmipur (Figures S2 and S3), (iii) the 12-month data series of hydraulic head from the three piezometers at each site

10 (Figures S4 and S5), (iv) the implications of a range of upper surface boundary conditions on the model results for Khulna and

11 Laksmipur (Figures S6 and S7), and (v) decomposition of the individual influences on groundwater heads, illustrated with 12 respect to Laksmipur (Figure S8). 


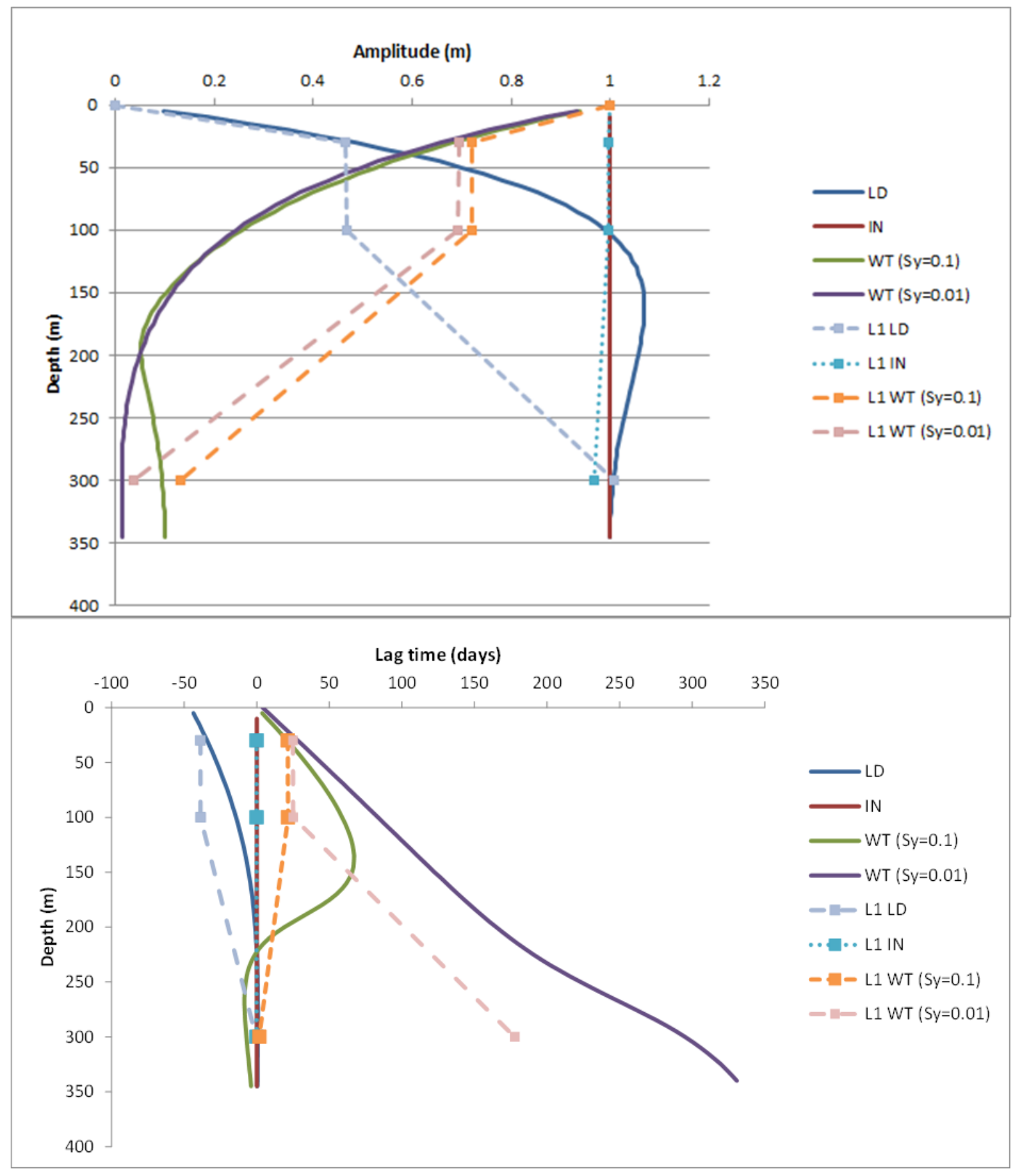

15 Figure S1. Amplitude (top) and phase lag (bottom) showing the effect of layering (dashed lines) in comparison to the 1D model 16 simulations of the uniform profile (solid lines, as in Fig. 5). The layers are as per Fig. 2 and results are reported at discrete 17 depths (i.e. $30 \mathrm{~m}, 100 \mathrm{~m}$ and $300 \mathrm{~m}$ ) corresponding to typical monitoring piezometer intervals in the BAS. The amplitude and 18 phase are found by taking the Fast Fourier Transform of the output heads. For the respective amplitude and phase lag of surface 19 vertical displacements, see Table S1. 


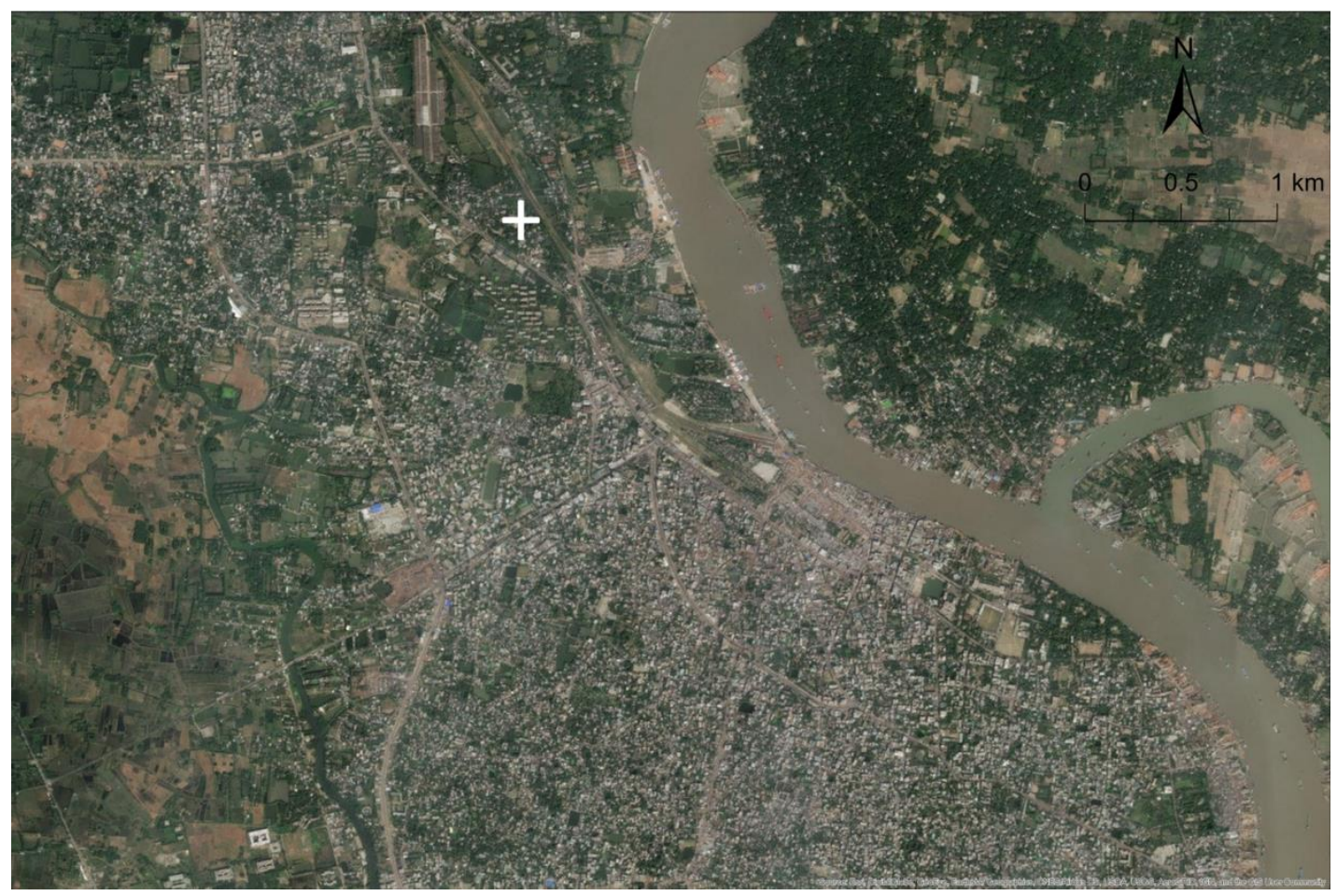

21

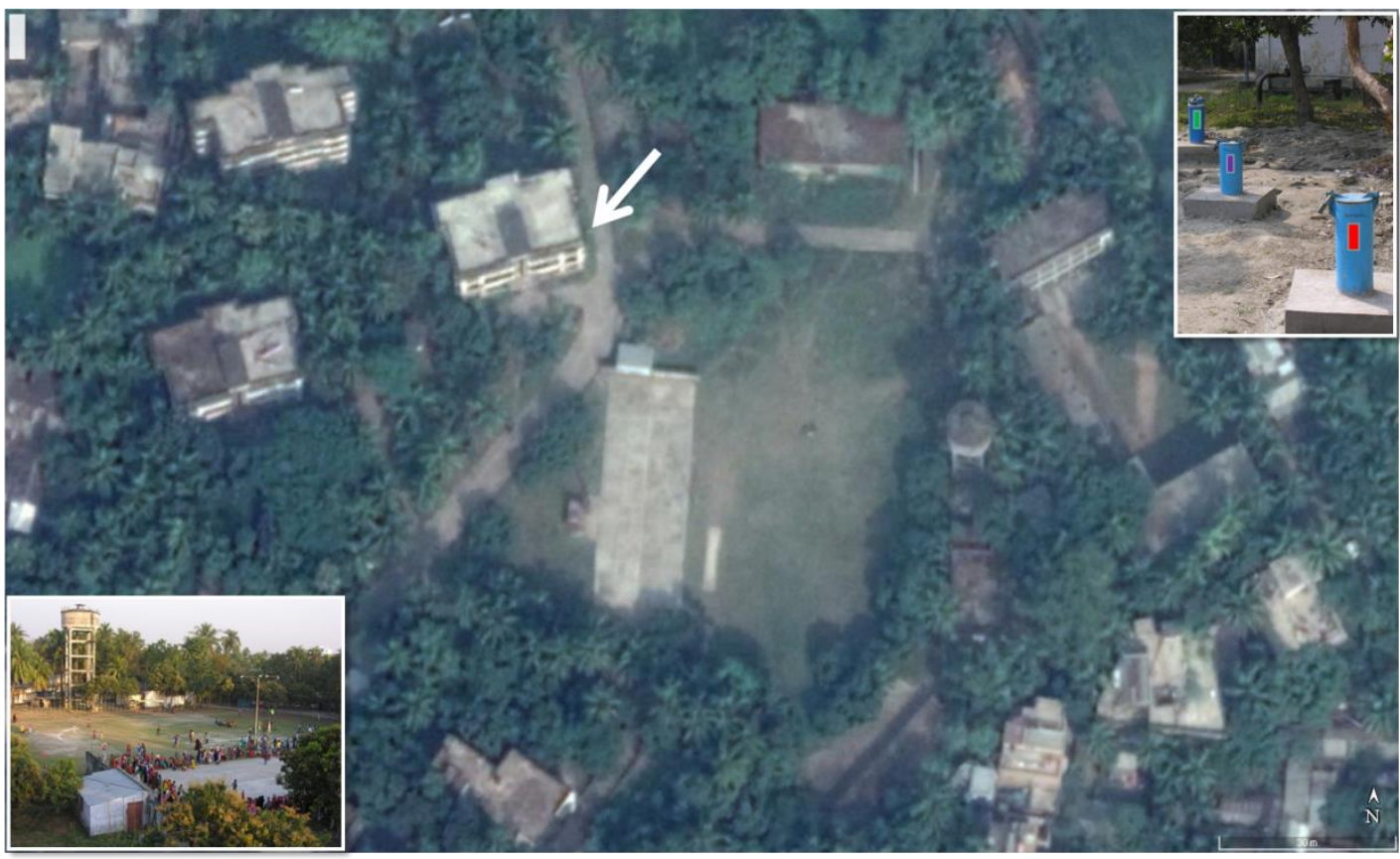

Figure S2. Khulna and the Rupsa River (top); the location of the BWDB compound is indicated. The Khulna BWDB compound and piezometers (bottom, and insets); the arrow marks the piezometers' location. The production boreholes are close to the base of the water tower. 

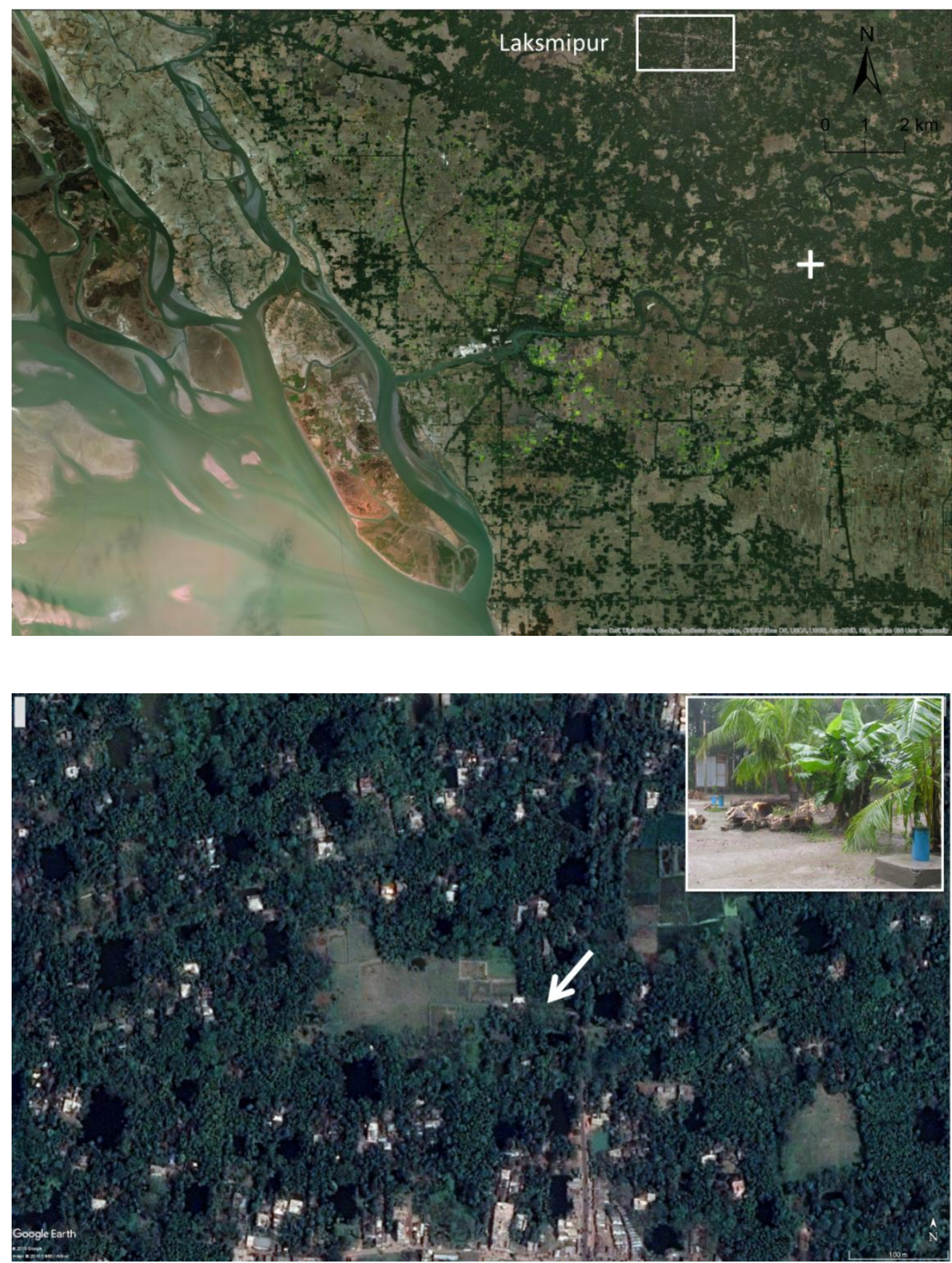

30 Figure S3. The Laksmipur piezometer site (top, indicated by + ) in relation to the Meghna River and Laksmipur town. The 31 Laksmipur piezometers' location in a rural area of tree plantations and scattered ponds is marked by an arrow (bottom and 32 inset). 

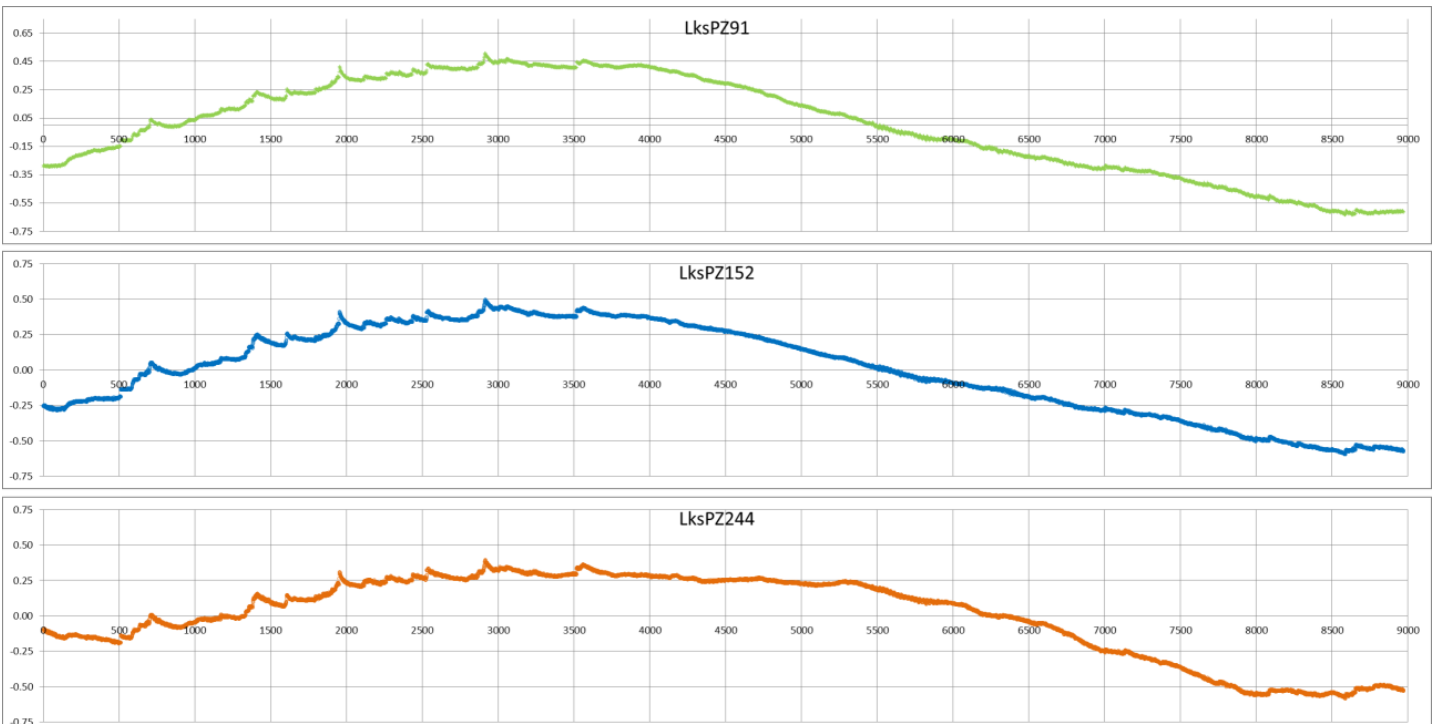

Figure S4. Hourly measurements of groundwater pressure made between May 2013 and June 2014 in three closely-spaced piezometers between 60 and $244 \mathrm{~m}$ depth at Laksmipur, Bangladesh, as hydrographs of equivalent freshwater head (the numbers indicate depth to the piezometer screen in metres). Vertical axis is in metres of freshwater head relative to the measurement period average; horizontal axis is hours from the start of monitoring $31^{\text {st }}$ May 2013 at 20:00. Further discussion of the Laksmipur hydrographs is provided by Burgess et al. (2017).
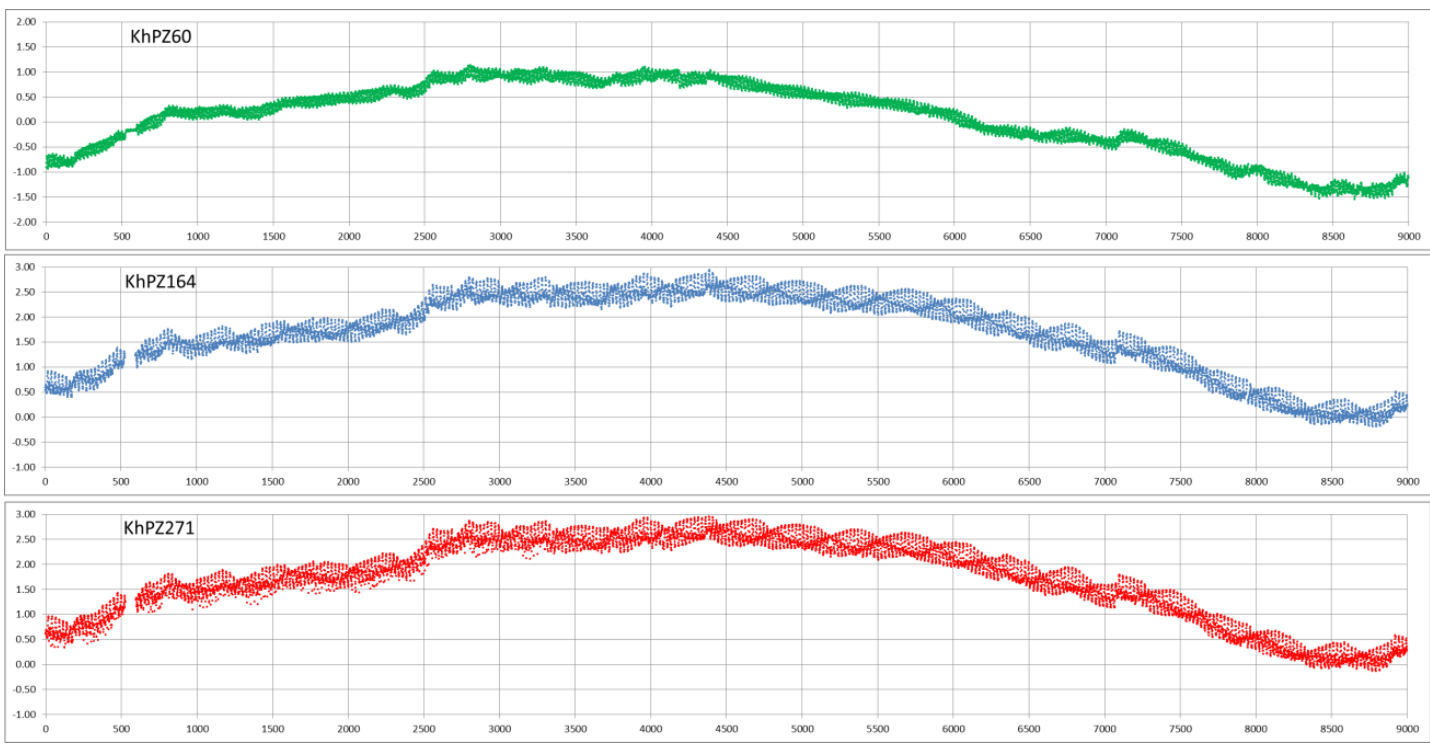

42 Figure S5. Hourly measurements of groundwater pressure made between May 2013 and June 2014 in three closely-spaced piezometers between 60 and $271 \mathrm{~m}$ depth at Khulna, Bangladesh, as hydrographs of equivalent freshwater head (the numbers indicate depth to the piezometer screen in metres). Vertical axis is in metres of freshwater head relative to the measurement period average; horizontal axis is hours from the start of monitoring on $27^{\text {th }}$ April 2013, at 11:30. Further discussion of the Khulna hydrographs is provided by Burgess et al. (2014). 

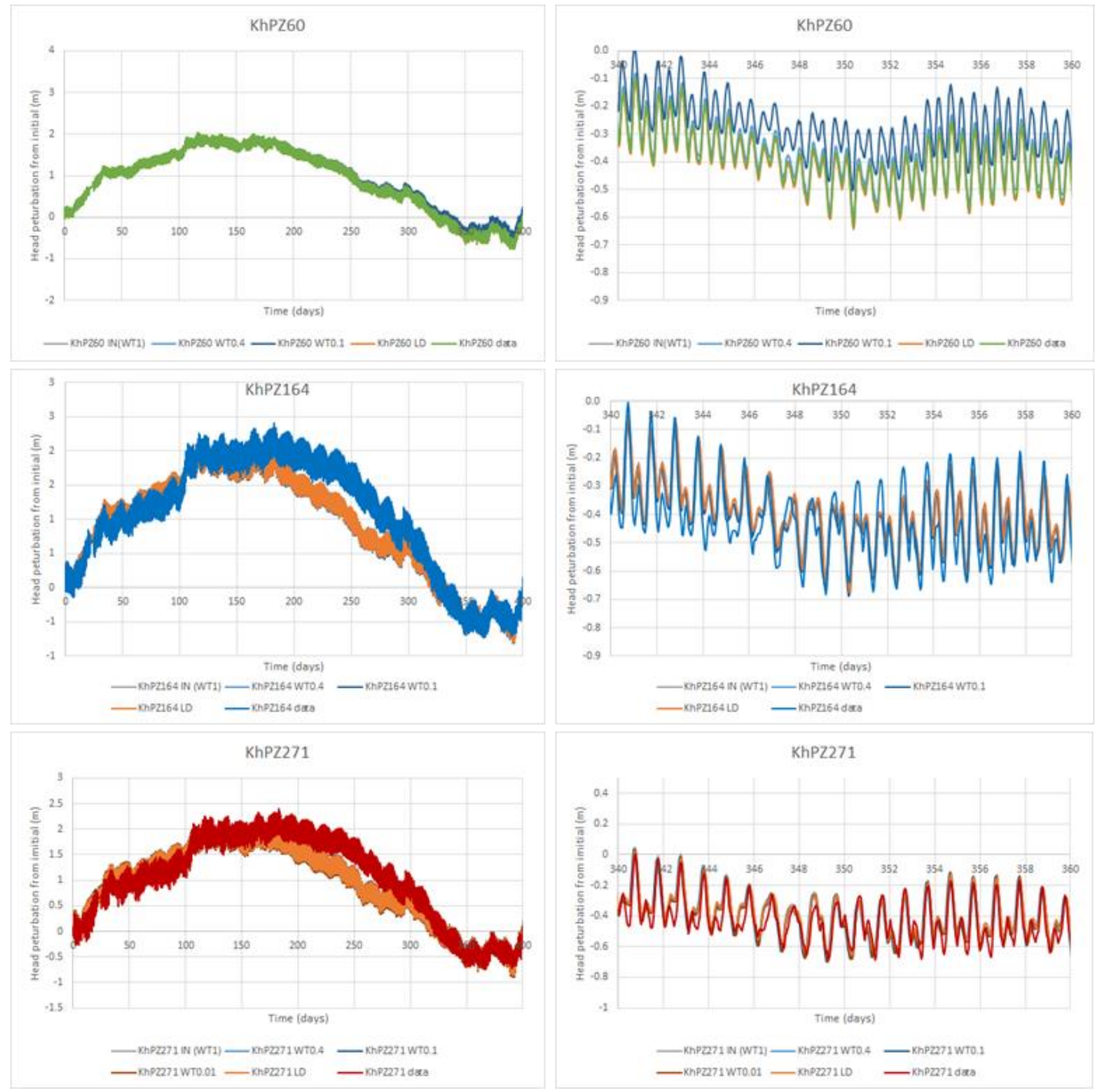

Figure S6. Khulna model simulations compared to data for each piezometer, with upper boundary conditions 'Water table' (WT), 'Load' (LD), and 'Inundation' (IN) as illustrated in Figure 2. The $S_{y}$ value is given for each WT condition. The small differences between the models are more clearly seen over a shorter time period (right hand column). 


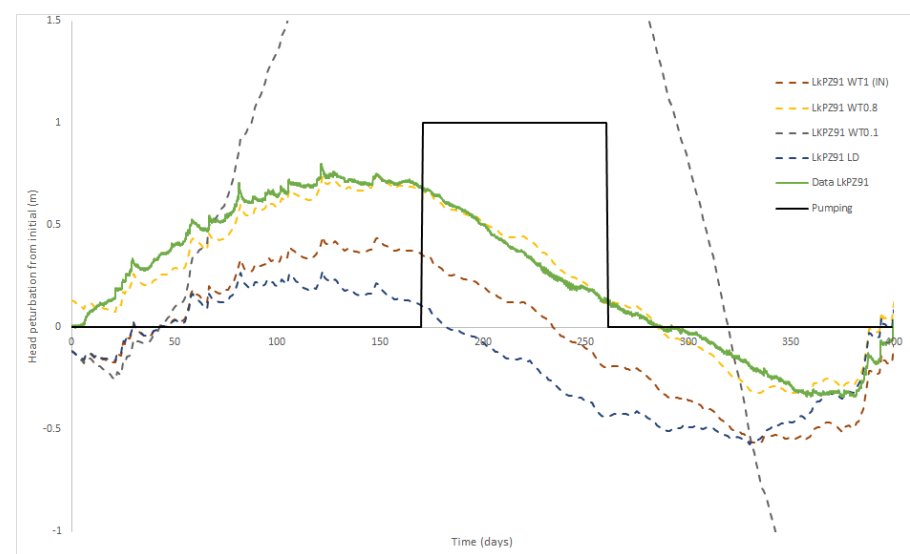

54

55
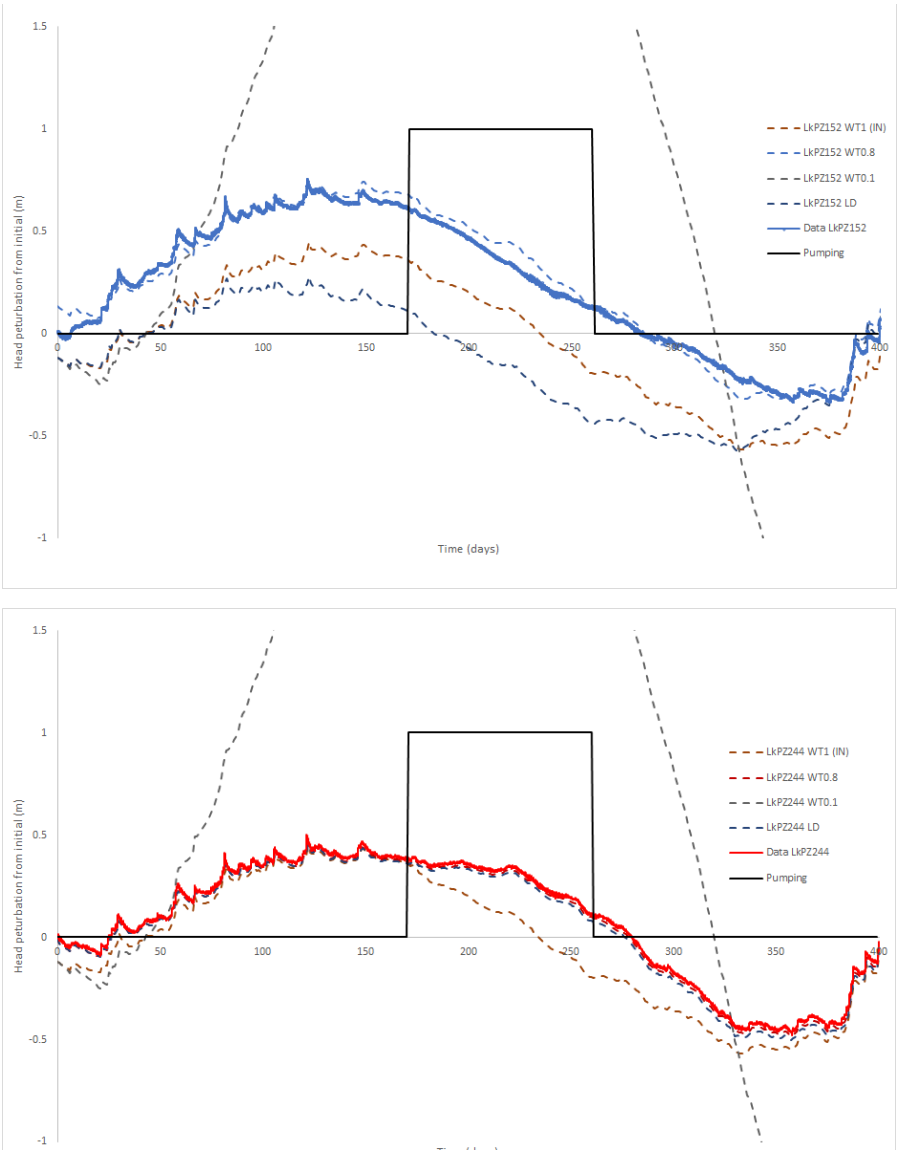

57 Figure S7. Laksmipur model simulations compared to data for each piezometer, with upper boundary conditions 'Water table' 58 (WT), 'Load' (LD), and 'Inundation' (IN) as illustrated in Fig. 2. The $S_{y}$ value is given for each WT condition. Time is taken 59 from $31 / 5 / 13$. 

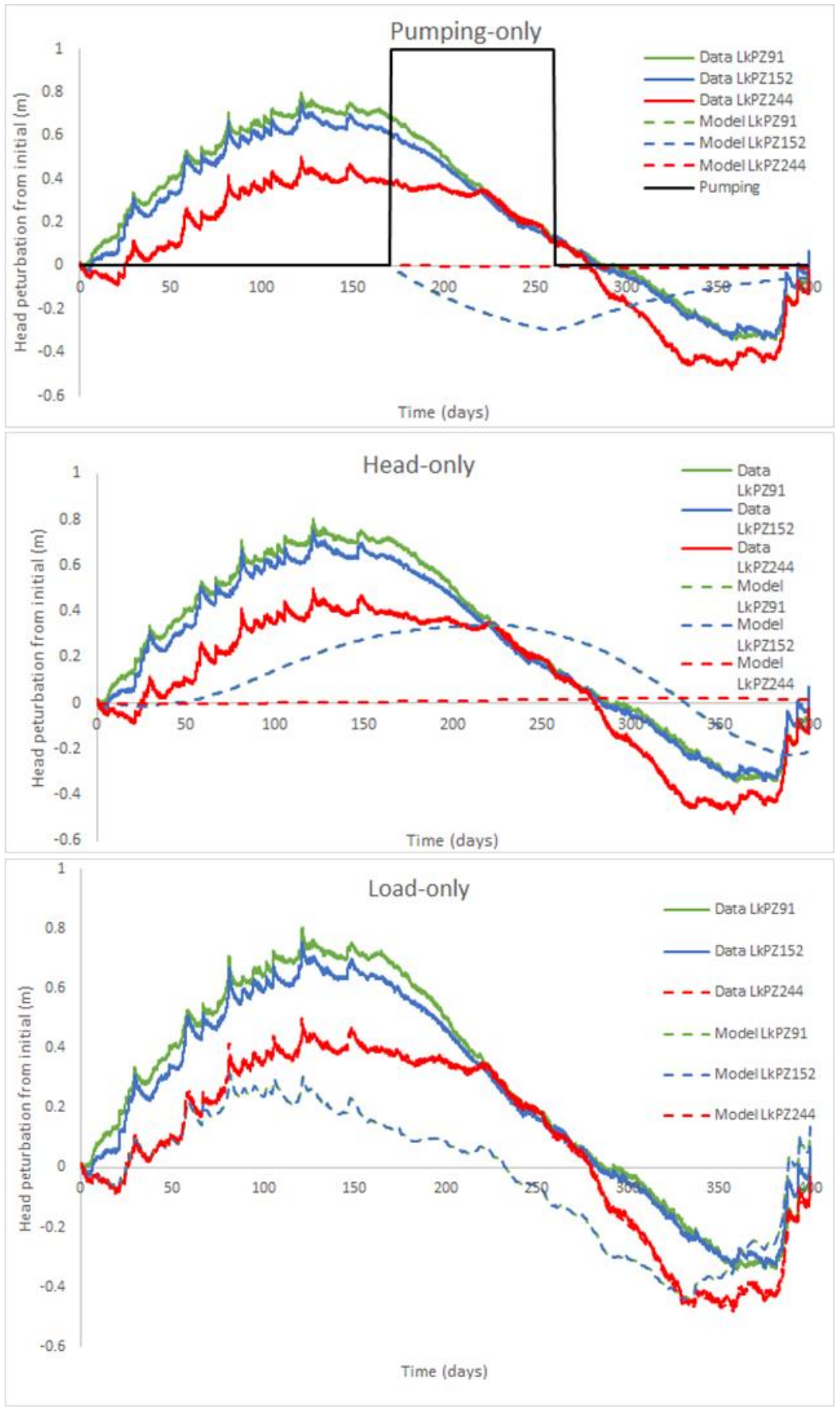

62 Figure S8: A decomposition of influences on groundwater heads, illustrated with respect to Laksmipur. 
63 Heads can be decomposed as the sum of the 'LD' and 'HO' loading contributions, i.e. $h_{L}(z, t)$ due to a mechanical load $L$ and

$64 h_{H}(z, t)$ due to a head change at the top boundary, $H$. Thus, $h(z, t)=h_{L}(z, t)+h_{H}(z, t)$. Equation [3] can be re-expressed as

65 (Anochickwa et al., 2012):

$66 \quad D \frac{\partial^{2}\left(h_{L}+h_{H}\right)}{\partial z^{2}}=\frac{\partial\left(h_{L}+h_{H}\right)}{\partial t}-\xi \frac{\partial L}{\partial t}$.

67 Taking each contribution in turn gives a differential equation and boundary conditions for each, i.e.:

$68 D \frac{\partial^{2} h_{L}}{\partial z^{2}}=\frac{\partial h_{L}}{\partial t}-\xi \frac{\partial L}{\partial t}$,

69 where, $h_{L}(0, t)=L$ and $h_{H}(0, t)=H=0$, and

$70 D \frac{\partial^{2} h_{H}}{\partial z^{2}}=\frac{\partial h_{H}}{\partial t}$,

71 where, $h_{L}(0, t)=L=0$ and $h_{H}(0, t)=H$

73 This decomposition is one way to understand why heads lead the applied load in the 'LD' case (Figure 5 and Section 3.3 of 74 the paper). For the 'LD' boundary, $h(0, t)=h_{L}(0, t)+h_{H}(0, t)=0$. Thus, $h_{H}(0, t)=-h_{L}(0, t)$, or $H=-L$. In this case, 75 the head and mechanical loading contributions are exactly out of phase, i.e. if $L(t)=H_{0} \cos (\omega t)$, then $H(t)=$ $76 H_{0} \cos (\omega t-\pi)$, giving rise to head peturbations that lead the loading signal for cyclic loads.

78 Applying such a decomposition to Equation (1), the contribution to pressures (or heads) due to groundwater abstraction $J$ is 79 included in the decomposition, i.e. $h(z, t)=h_{L}(z, t)+h_{H}(z, t)+h_{J}(z, t)$. This is illustrated for the simulation of Laksmipur 80 (Figure 7) in Figure S8 (top), which shows a classic drawdown and recovery due to groundwater pumping affecting LkPZ91 81 and LkPZ152 but not the deepest piezometer LkPZ244. The head change at LkPZ91 and LkPZ152 due to the hydraulic load 82 at the surface (Figure S8, middle) considerably lags the surface water load and the short term rainfall events have dissipated; 83 none of hydraulic load penetrates to LkP244. In contrast, the head change due to the mechanical load (Figure S8, bottom) 84 includes short-term rainfall events at all levels, the LkPZ244 hydrograph matching the assumed mechanical load (confirming 85 that the assumed conditions result in the deep piezometer acting as a weighing lysimeter), whereas the LkPZ91 and LkPZ152 under-represent the observed trends in head. The overall response is the sum of the decomposed responses at all levels (see also Figure 7 of the main paper). 


\begin{tabular}{|l|l|l|l|l|}
\hline & \multicolumn{2}{|l|}{ Lag (days) } & \multicolumn{2}{l|}{ Amplitude (mm) } \\
\hline Boundary & Uniform & Layered & Uniform & Layered \\
\hline LD & 141.4 & 144.0 & 5.27 & 3.00 \\
\hline IN & 184.0 & -178.7 & 0.38 & 0.37 \\
\hline WT S S $=0.1$ & -44.7 & -44.2 & 0.45 & 0.33 \\
\hline WT S $S_{y}=0.01$ & -44.4 & -43.7 & 4.95 & 2.72 \\
\hline
\end{tabular}

89 Table S1. Amplitude (mm) and lag (days) of the surface vertical displacements for the 1D model simulations of the uniform 90 and layered BAS profiles under sinusoidal hydrological loading (for explanation see Sections 2.5 'Upper boundary conditions' 91 and 3 'Forward modelling results' of the main paper). The layers and parameter values are as per Fig. 2. The amplitude and 92 phase are found by taking the Fast Fourier Transform of the output displacements. For the respective amplitude and phase lag 93 of groundwater heads, see Fig. S1. 